\title{
Gênese, evolução e universalidade dos direitos humanos frente à diversidade de culturas
}

\author{
ETIENNE-RICHARD MBAYA
}

$\mathrm{E}$ M VISTA DO tempo acadêmico de uma hora, que me foi concedido, e no intuito de clareza na apresentação de meu tema, decidi dividir minha exposição em três partes: os direitos humanos em algumas tradições culturais; a universalidade dos direitos humanos e sua relação com a democracia social; a democracia como direito e condição do desenvolvimento da paz social, tendo em vista o exemplo do processo democrático atual na África

\section{Introdução}

Os direitos humanos exprimem uma antinomia fundamental na sociedade humana, antinomia que vai da relação entre Homem e sociedade à relação do indivíduo com todos os seus congêneres.

Foi necessário muito tempo para que esse conflito fundamental se tornasse um problema social. Durante séculos, a Igreja havia suprimido a antinomia entre Homem e sociedade, substituindo-a pela panacéia transcendente da eternidade, no intuito de diminuir o interesse do homem pela sua vida terrestre transitória. Em lugar do Homem e da Sociedade, a Igreja oferecia aos pobres e aos ricos a máxima o Homem e o Reino de Deus, esforçando-se por manter a riqueza dos ricos e a pobreza dos pobres.

Portanto, não é de surpreender que a exigência dos direitos humanos se torne, ao mesmo tempo, um problema filosófico e político, numa época em que a situação da adscriptio globae está em vias de desaparecimento e a sociedade se prepara para o triunfo do proletariado industrial - momento em que o sistema feudal está decadente ou em ruínas, com o desenvolvimento da propriedade privada que deve depender da livre empresa e da liberdade dos empreendedores para ser viável.

Com a escravidão, o colonialismo e, subseqüentemente, o advento do fascismo, retomou-se o exame da recusa dos direitos humanos. Embora em sua forma original a escravidão, o colonialismo e o fascismo tenham desaparecido, reapa- 
recem de outro modo, em nossos dias, sendo o mesmo, no entanto, seu efeito no tocante à violação do direitos humanos. As novas formas são, para citar apenas algumas, as ditaduras e o neocolonialismo.

Tendo herdado, portanto, um passado histórico, o fenômeno dos direitos humanos participa também de um presente, cujos dados estão em evolução constante. A manifestação específica desses direitos nos obriga a considerá-los como objetos científicos com campo de estudo determinado, se se quiser que o respeito a eles não seja ditado pelos imperativos formais de uma dogmática, mas, ao contrário, se apóie em dados científicos.

\section{Exclusividade dos direitos humanos}

A história dos direitos humanos é caracterizada pela noção de exclusividade e, mesmo no mundo atual, tais direitos tendem a funcionar em favor dos privilegiados (1).

Com a criação das Nações Unidas e a adoção dos princípios da Carta da ONU, além da Declaração Universal dos Direitos do Homem, entre outros instrumentos internacionais, finalmente foi abandonada, ao menos teoricamente, a idéia da exclusividade dos direitos humanos. Vivemos, desde 1945, um período de reconhecimento da sua universalidade e inclusividade, sendo, também, um período de reivindicações dos povos no sentido de exercerem o direito à autodeterminação como um direito dos povos e do homem. É o momento da democratização, da descolonização, da emancipação, da luta contra o racismo e todas as formas de discriminação racial. $\mathrm{O}$ direito à existência, à vida, à integridade física $\mathrm{e}$ moral da pessoa e à não-discriminação, em particular a racial, são normas imperativas da comunidade internacional ou da natureza do ius cogens.

Em geral, os que gozam de liberdade são de um lado privilegiados, the Haves, $\mathrm{e}$, de outro, os setores da sociedade nacional e internacional ligados à ordem atual das coisas têm interesses a proteger, entre os quais o de defender o status quo, assim como estão à sua disposição os meios políticos e econômicos para a defesa da ordem existente.

Contrariamente a eles, a maioria da humanidade possui aspirações que se traduzem por um desejo de mudança, de uma nova ordem social. Os desfavorecidos, as vítimas da opressão, discriminação e exploração pedem, como indivíduos e na condição de grupos, a participação, a emancipação, a autodeterminação e uma repartição justa e eqüitativa de riqueza e recursos. Tais reivindicações fazem parte de um movimento de libertação com vistas a substituir sistemas e práticas de opressão e exploração por estruturas e relações baseadas na justiça e no respeito aos direitos humanos para todos.

Como se sabe, a Declaração Universal dos Direitos do Homem tinha limites, não impondo, por exemplo, obrigação alguma. Um grande número de direitos era formulado de maneira imprecisa e nenhum organismo de controle fôra previsto, assim como estavam inclusos os direitos coletivos. 
A evolução posterior contribuiu para eliminar um grande número de tais imperfeições, embora muita coisa ainda esteja por fazer. Desse modo, desde 1946 a evolução da ONU assumiu as seguintes dimensões:

- precisar e elaborar o teor real das normas;

- tornar mais claras as obrigações dos Estados correspondentes a tais normas;

- estabelecer mecanismos de controle da execução dos direitos humanos pelos Estados;

- estabelecer procedimentos que permitam reagir contra as violações;

- descobrir as ligações entre os direitos humanos e os outros problemas fundamentais da comunidade mundial, tais como o desenvolvimento e a busca da paz (2).

Embora possa ser sustentado que todos os Estados-membros aceitam as obrigações decorrentes da Carta das Nações Unidas, inclusive a de encorajar "o respeito universal e efetivo dos direitos humanos e das liberdades fundamentais para todos sem distinção de raça, sexo, língua, ou religião (art. 55c), pode-se igualmente sustentar que a Declaração Universal tomou o cuidado de mencionar claramente tais direitos e, em conseqüência, todos os membros se viram obrigados a incentivar o respeito efetivo desses direitos. Entretanto, revelou-se necessário e indispensável precisar a força obrigatória dos direitos humanos, pela adoção de certo número de convenções que os Estados tinham a faculdade de ratificar. As mais importantes convenções desse tipo são as relativas aos direitos civis e políticos (1966), aos direitos econômicos, sociais e culturais (1966), as convenções contra a discriminação, às quais é preciso acrescentar as adotadas por organizações regionais (Convenção Européia dos Direitos Humanos e das Liberdades Fundamentais, Convenção Americana relativa aos Direitos Humanos, Carta Africana dos Direitos Humanos e dos Povos).

Por isso, se violações contínuas existem, o problema não está na inexistência de convenções, mas na necessidade de se dar contornos mais precisos aos direitos e obrigações, além de fazer funcionar mecanismos internacionais suficientemente seguros para vigiar sua aplicação e reagir contra violações. Tais mecanismos ajudariam a dar consistência cada vez mais específica e pormenorizada aos direitos gerais e vagos contidos na Declaração Universal.

À sua maneira, as grandes correntes de pensamento propuseram, já de há muito, certo ideal dos direitos humanos; mas foi apenas ao longo das últimas décadas e, sobretudo, desde a última guerra mundial, que se buscou dar a eles uma formulação precisa e jurídica com relação à qual os Estados poderiam se comprometer.

A despeito da ancianidade da concepção dos direitos humanos e da larga adesão encontrada por ela e malgrado a longa evolução dos meios empregados na proteção de alguns desses direitos por conjuntos de leis, a proclamação sistemática das declarações dos direitos humanos é um fenômeno recente na história. 
Para compreender a gênese de sua noção e sua formulação atual, efetivamente é forçoso distinguir, de um lado, as origens ou raízes mais ou menos longínquas nas diferentes tradições e filosofias e, de outro, as fontes mais imediatas dos textos atuais concernentes aos direitos humanos.

\section{Direitos do Homem sujeito de direitos interno e externo}

Os direitos humanos correspondem a certo estado da sociedade. Antes de serem inscritos numa constituição ou num texto jurídico, anunciam-se sob a forma de movimentos sociais, de tensões históricas, de tendência insensível das mentalidades evoluindo para outra maneira de sentir e pensar.

Na precipitação histórica que agita o mundo, deveria ser dosada meticulosamente a parte relativa aos sentimentos, temperamento, cultura, religião, relação entre poder e sociedade civil. Se os direitos humanos possuem enraizamento social preciso e incontestável, ainda assim não são o fruto de simples determinismo social; mesmo movido por potentes molas sociais, o homem conta como tal em sua interpretação da história, em sua maneira de governar e pensar as forças individuais e coletivas que o agitam e provocam. Trata-se do homem como sujeito dotado de necessidades, desejos, aspirações, sentimento e razão. Não é somente um ser privado e um ser social, é, também, um animal político. A política é um cruzamento no qual atuam contraditoriamente as exigências do público e do coletivo, do natural e do civil; tal cruzamento se estabelece sempre numa relação de forças representada por grupos com interesses divergentes e freqüentemente opostos. A tarefa fundamental do político é precisamente a regulamentação dessas forças.

Tal parece ser o caso da série dos pensadores que pontilham os séculos XVII e XVIII, cujo mérito - um dos mais altos - terá sido permitir a redação de numerosas reivindicações ou declarações dos direitos, na Inglaterra, na França e nos Estados Unidos da América.

Desde então, os direitos humanos situam-se num combate de idéias, constituindo o florão de uma vigilância do espírito face às pressões dos poderes estabelecidos, dos hábitos mentais, dos modos de governo herdeiros de ordens mais antigas. Como o espírito, a idéia é dinâmica; ela atravessa o tecido da história para inventar algo novo; ela perturba. Não se trata de um simples reflexo de certo estado de coisas. Igualmente, a Declaração dos direitos do homem é esse movimento do espírito ao mesmo tempo em que responde à necessidade elementar de proteção, no plano físico e moral, contra os abusos de poder e as desigualdades das relações de força.

Os direitos humanos situam-se no plano das idéias, da ideologia, mas esta não é o que pensamos habitualmente, quando a colocamos sistematicamente em oposição à ciência.

Afirmar que tal partido é o único a ter razão, o único a ter acesso ao objetivo, significa, na prática, exatamente o mesmo que afirmar que nada é universal- 
mente verdadeiro. Nos dois casos, o outro é negado em seu direito à existência, à verdade, à amizade. As ideologias executam este golpe de fraqueza eficaz que consiste em decretar de modo absoluto onde está o verdadeiro e o falso. Não é a elas, portanto, que podemos nos referir para defender o direito dos outros; são de per si totalitárias, tendo necessidade de sistemas fechados. Nesse sentido, a defesa ideológica dos direitos humanos não é apenas ineficaz, é perigosa, já que reduz ao prosélito e à opinião preconcebida o que pertence à consciência universal. A neutralidade só é um valor positivo quando se torna condição necessária e ativa para um engajamento irrestrito, já que situado no nível do direito.

Se é preciso deixar de lado as ideologias, fica difícil apelar aos Estados: eles mesmos são, o mais das vezes, prisioneiros de seu próprio aparelho de razões, das quais a razão d'Estado não é nem de longe a mais razoável. A ideologia é um particularismo guindado à condição de absoluto; a cultura particular de um povo, ao contrário, é uma sensibilidade comum e relativa que se abre para as questões universais.

Portanto, é no nível da diversidade das consciências populares que podemos buscar o princípio efetivo de uma solidariedade internacional. É no aprofundamento das diversas experiências vividas em meio ao mundo que encontraremos as expressões da necessidade universal de criar o Homem livre e solidário.

Do século XVII ao XX, todas as declarações dos direitos do homem proclamam os seguintes direitos imprescritíveis: a liberdade, a propriedade, a segurança e a resistência à opressão.

Tendo afirmado sua existência depois da Segunda Guerra Mundial, os direitos humanos ocupam, desde então, lugar à parte no direito internacional, cujos especialistas têm dificuldade em integrá-los a seu esquema teórico e intelectual, de tal modo que as costuras ficam visíveis e os artifícios abundantes, quando os internacionalistas se esforçam para incluí-los na sistemática de direito internacional geral.

Tais reflexões nos conduzem igualmente a um tema que é freqüentemente evitado: a universalidade dos direitos humanos face à diversidade das culturas.

A percepção dos direitos humanos está condicionada, no espaço e no tempo, por múltiplos fatores de ordem histórica, política, econômica, social e cultural. Portanto, seu conteúdo real será definido de modo diverso e suas modalidades de realização variarão. Em vista de tal diversidade, reflexo da própria diversidade das sociedades e das concepções do homem, uma pergunta essencial se faz: há uma concepção universal dos direitos humanos? Mais precisamente, tais direitos, cuja universalidade somos levados a admitir de chofre, referindo-nos a muitas declarações, pactos, cartas e convenções, não seriam produto de condições históricas, especificamente ocidentais?

Das várias perguntas e respostas que certamente existem, manteremos duas fundamentais. A primeira fundamenta-se no fato do reconhecimento universal da humanidade como espécie peculiar, distinta de todas as outras vivas, o que implica 
uma natureza própria ao homem, idêntica em todos. Tal resposta encontra seu fundamento no direito natural. A segunda tem sua base nas concepções positivistas que fazem com que o direito seja freqüentemente considerado como o resultado de um acordo entre interesses em conflito no seio de certa sociedade humana. Nessa concepção, os direitos humanos não são considerados como inerentes a qualquer ser humano, mas concedidos e garantidos pelos órgãos do Estado, sendo tratados, portanto como "uma noção de direito constitucional e internacional cuja missão é defender de maneira institucionalizada os direitos da pessoa humana contra os excessos de poder cometidos pelos órgãos do Estado, promovendo, paralelamente, o estabelecimento de condições humanas de vida, assim como o desenvolvimento multidimensional da personalidade humana" (3).

Será necessário notar que essa concepção positivista conduz inevitavelmente a definições e sobretudo a concretizações discordantes? Como tais concretizações dependem apenas dos órgãos do Estado, os direitos humanos correrão o risco de só serem reconhecidos e respeitados na medida que forem julgados compatíveis com princípios e objetivos de certo sistema político e econômico. Desse modo, certos Estados ocidentais privilegiarão as liberdades clássicas; os Estados socialistas darão mais importância aos direitos sociais e econômicos; os Estados do Terceiro Mundo assegurarão que o subdesenvolvimento impõe restrições à proteção dos direitos humanos, pois, segundo eles, "os direitos fundamentais do homem, quaisquer que sejam seu conteúdo e natureza, não podem ter alcance verdadeiro a não ser na medida que as condições sócio-econômicas permitam (4). Levando-se em conta a defasagem que caracteriza as relações Norte-Sul, torna-se cada vez mais difícil recusar cientificamente tal argumento.

\section{Direitos humanos}

\section{e algumas grandes tradições culturais}

É no mínimo duvidosa a tentativa de reunir citações de textos que remontam ao alvorecer da história escrita da humanidade ou às escrituras sagradas das principais religiões, ou mesmo coligir citações de textos dos grandes filósofos e teóricos da sociedade, para demonstrar que os direitos humanos sempre foram reconhecidos ou reclamados. As exigências das ciências históricas e sociológicas (inclusive a história e a sociologia das religiões) precatam-nos contra esse tipo de apologia ou interpretação seletiva. Se formos, no entanto, muito prudentes quanto às conclusões a serem tiradas, poderemos procurar em origens mais longínquas os elementos duráveis e presentes atualmente nos grandes sistemas de pensamento que expressam os valores fundamentais da noção atual dos direitos do homem. Dito de outro modo: trata-se de assinalar preceitos que cada um encontra em sua própria cultura, permitindo reconhecer-se no atual combate em favor dos direitos humanos, levando-se em conta, entretanto, os eventuais obstáculos que certas crenças ou práticas tradicionais podem constituir.

Para ilustrar a grande variedade de atitudes que participam desse diálogo permanente das culturas, citemos algumas de suas tradições, sem, no entanto, analisá-las. 


\section{Tradição chinesa e budismo}

Por ocasião de uma pesquisa feita em 1947 a respeito dos fundamentos filosóficos dos direitos humanos, o especialista na tradição chinesa observou que os pensadores chineses de outrora pouco se preocuparam com a questão, ou pelo menos, não da mesma maneira que no Ocidente, observando ainda que se procuraria em vão uma declaração dos direitos do homem na obra dos filósofos e nas constituições políticas da China antes da introdução no país da noção ocidental de direito. Nem por isso deixou de consignar que tal noção dos direitos humanos apareceu muito cedo e o direito de o povo se revoltar contra o soberano tirânico foi também logo reconhecido.

Em um colóquio sobre o lugar dos direitos humanos segundo as diferentes perspectivas religiosas (Bangkok, 1979), o representante budista, em sua fala, considerou constituir o budismo um esforço de conceitualização e de método para apreender a verdade global, mostrando o caminho a seguir. Longe de ser fatalista a propósito da vida, busca ultrapassar a aparência da natureza humana e suas tendências para se prender ao potencial criador e construtivo do homem, das primeiras às últimas etapas de sua libertação. Esse é o quadro em que a liberdade e os direitos humanos assumem sua verdadeira significação.

\section{Judaismo, cristianismo e islamismo}

Depois de terem sido definidos os limites da tentativa de reunir citações edificantes sobre direitos humanos, paz etc. tirados da literatura religiosa, pode-se dizer que o judaísmo fornece exemplos da maneira pela qual sua tradição enfrenta problemas concretos nesse campo.

Ao mesmo tempo, também podem ser notados paradoxos que a história judaica apresenta, introduzindo-se uma discussão entre dois mestres rabínicos; o que mostra, na Bíblia e na tradição dos judeus, o caráter fundamental da dignidade e dos direitos humanos (assim como nossos deveres com relação ao próximo).

Por meio de seus leigos, teólogos, missionários e hierarquia, a Igreja católica participa da longa busca do homem no sentido da descoberta de seus direitos. O mesmo ocorre com a Igreja protestante a qual considera parte do trabalho que, nos dias de hoje, ela pode e deve prestar à sociedade, o empenho a serviço dos direitos humanos.

Por sua vez, o muçulmano considera poder a expressão ocidental moderna direitos individuais ser traduzida, em contexto islâmico, por direitos de sujeitos morais centrados na dignidade natural da humanidade e sobre o eu. Direitos sociais poderiam ser entendidos como direitos do ser comunitário, enfatizando-se, nesse caso, o nós. Aliás, existe uma Declaração Islâmica Universal dos Direitos do Homem, de origem não-governamental, cuja introdução afirma ter o Islão dado à humanidade, há 14 séculos, um código ideal dos direitos humanos.

Eles têm como objetivo conferir honra e dignidade à humanidade e eliminar a exploração, a opressão e a injustiça. 


\section{Humanismo africano}

Com todos os problemas e contradições - imensos mas não insuperáveis uma dimensão característica da África e sua contribuição tradicional à idéia dos direitos do homem é precisamente seu humanismo, revelado de acordo com três pontos de partida e permitindo a ligação com os conceitos modernos nesse campo:

- o humanismo africano não fragmenta o indivíduo para destacar vários de seus componentes, com o intuito de valorizar o aspecto econômico em detrimento de outras características: o homem é uma totalidade. A revolução industrial imoral das sociedades ocidentais, que baseou seu sistema de valores numa análise puramente econômica, em sua essência é contrária ao humanismo africano;

- não aliena o indivíduo, visto não o considerar isoladamente, mais ou menos independente da sociedade da qual ele faz parte. Nenhum homem é uma ilha: esse ditado mostra-se particularmente verdadeiro na África. A família ampliada - e não a individual ou nuclear - é o bloco fundamental da sociedade. As relações no interior da família, do clã e da tribo não são pontos de partida artificiais ou superficiais, mas dimensões reais, enriquecedoras e calorosas que conferem sentido à vida individual;

- os círculos concêntricos, embora unos das relações individuais por se ampliarem da relação com os parentes até as do clã e da tribo, interpretam a realidade social, objetiva, de modo a compreender a humanidade como uma fraternidade. É verdade que sempre houve conflitos em diversos níveis, sendo preciso considerá-los como meios de defesa de interesses especiais. Além disso, são meios extremos, utilizados nos momentos em que - tal como ocorre certas vezes - os esforços de conciliação e de arbitragem fracassam. Em todo caso, na condição de aspectos negativos, os próprios conflitos provam a regra geral das inter-relações humanas.

Silenciadas em geral, porque sem interesse jornalístico, as relações na África tradicional sempre foram de preferência positivas e não negativas (5).

Para explicar a natureza do humanismo africano em sua relação com a formulação atual dos direitos humanos é necessário levar em consideração três critérios de valor:

- o humanismo africano não separa o indivíduo e também não suprime seus diferentes componentes com o fito de privilegiar sua dimensão material em detrimento das outras dimensões;

- não aliena o indivíduo da sociedade, isto é, os dois formam uma unidade dialética de relações indispensáveis à existência de ambos. Em tal situação, o indivíduo não é o oposto da sociedade mas, ao contrário, sua parte vital que só pode se justificar nela e por meio dela. Os direitos e os deveres de uma pessoa existem como deveres da sociedade e serão exercidos nessa condição; 
- o humanismo africano detém a visão geral dos problemas vitais da personalidade ética da África face aos direitos humanos.

Poder-se-iam multiplicar à vontade os exemplos e encontrar para cada um a mesma dificuldade: todo sistema de pensamento situa-se num contexto histórico e social, tendo seu próprio sistema de valores e referências. Desse ponto de vista, um lugar particular deve ser reservado ao pensamento marxista e à tradição liberal.

\section{Pensamento marxista}

Karl Marx denuncia o caráter de classe dos direitos humanos como a muralha do homem egoísta, no caso, do homem como membro da sociedade burguesa. Não é menos verdadeiro que a tradição dos pensadores socialistas que precederam e sucederam Marx, assim como seus próprios escritos visam, antes de tudo, à liberação do homem de toda forma de opressão e exploração, ou seja, o pleno respeito aos direitos humanos tais como são formulados hoje. O primeiro texto político de Marx, jamais publicado, era uma longa série de artigos sobre a liberdade da imprensa na Rheinische Zeitung de maio de 1842, qualificados por Jean Elleinstein, em sua obra Marx, sa vie, son oeuvre como uma vibrante defesa das liberdades públicas. Até Raymond Aron, defensor do liberalismo contra os marxistas, confessa que, no seu início, Marx não quer retroceder no tocante às conquistas da Revolução francesa, mas sim completá-las. Democracia, liberdade e igualdade, são valores que se impõem a ele de modo evidente. Marx traz à teoria dos direitos humanos, entre outras coisas, a distinção entre liberdades formais, políticas e pessoais, usufruídas efetivamente apenas pelos burgueses, e liberdades reais, de que a maioria dos homens não poderia gozar a não ser após uma revolução das condições sociais e econômicas

Qualquer que seja o argumento a respeito dos regimes que se valem do marxismo, para muitos ele fornece elementos de análise essenciais à compreensão da problemática dos direitos humanos na sociedade contemporânea.

\section{A tradição liberal e as fontes dos direitos humanos em direito internacional}

A formulação atual dos direitos humanos tem como origem direta a tradição, no Ocidente, do século das luzes, refletindo, dessa forma, as condições econômicas e sociais da época. É longa a história da discussão filosófica dos direitos humanos, da dignidade, da fraternidade humana e da cidadania comum na sociedade universal; ultrapassa os limites estreitos da tradição ocidental, mas, em contrapartida, a história das declarações dos direitos do homem é curta e tem seu começo no Ocidente.

Formulando a pergunta sobre qual a influência da tradição ocidental na formação atual dos direitos humanos é que poderemos examinar a de sua universalidade. Freqüentemente ouve-se dizer que os direitos humanos são de inspiração ocidental e que isto não significa servirem apenas para perpetuar a dominação capitalista e imperialista dos países ocidentais. 
Embora empreste muito da tradição e da ideologia ocidental, a Declaração Universal não pode ser confundida com elas. A razão está no alargamento progressivo dos direitos humanos em virtude da participação de representantes de outro sistema de pensamento na redação de textos fundamentais. Na Declaração, o lugar concedido aos direitos econômicos, sociais e culturais mostra do modo mais nítido que se foi além da tradição ocidental; pois não seria seu individualismo e sobretudo o livre exercício do direito à propriedade e ao comércio que permitiriam a acumulação capitalista nos séculos XVIII e XIX com suas conseqüências: opressão dos trabalhadores e expansão colonialista? Felizmente não é mais assim a concepção dos direitos humanos em sua formulação atual.

Podemos, portanto, afirmar que a ideologia liberal e capitalista da tradição ocidental se encontra em larga margem ultrapassada pela formulação atual dos direitos humanos no plano internacional. Assim, em 1977, a Assembléia Geral das Nações Unidas tinha deixado claro: a experiência e a contribuição do conjunto dos países - desenvolvidos e em desenvolvimento - deverão ser levadas em consideração por todos os órgãos do sistema das Nações Unidas, em suas atividades relativas aos direitos humanos e às liberdades fundamentais. É de cada um, portanto, a maneira de sentir e definir tais direitos com relação às suas origens culturais $\mathrm{e}$ preferências filosóficas.

Doravante existe uma linguagem que permite aos representantes de todos os povos se pronunciarem: trata-se essencialmente dos tratados internacionais, do costume internacional e dos princípios gerais de direito, nos quais se pode encontrar o catálogo dos direitos atualmente reconhecidos no plano internacional. Trata-se, igualmente, do discurso jurídico-diplomático, que está freqüentemente distanciado daquilo que é vivido pelos povos. Todavia, o processo de elaboração das normas implica sua ancoragem nas condições sociais e econômicas, nas necessidades do homem. Isto dá uma idéia da extensão dos direitos humanos e dos compromissos formais dos Estados em respeitá-los.

\section{Direitos humanos e a filosofia do direito}

Outrora, a questão da universalidade ou da aplicabilidade à cultura dizia respeito à filosofia do direito. Nessa questão, as outras disciplinas jurídicas tinham apenas um papel secundário. Se a teoria atual dos direitos humanos retoma em parte tal tradição, aparece também, e ao mesmo tempo, como uma inovação.

Uma das dificuldades maiores contra as quais se choca a teoria atual dos direitos humanos reside no fato de implicar a colaboração de disciplinas com orientação jurídica e de ciências estranhas ao direito as quais, por tradição, estabeleceram perspectivas próprias, freqüentemente restritas em demasia, de tal sorte que as primeiras têm a tendência a fazer da universalidade dos critérios de valores um dogma, ao passo que as outras pendem para a tese de um relativismo sem restrição.

Não é mais necessário argumentar longamente para refutar a afirmação dogmática da universalidade dos critérios de valores, que se revela indefensável, e isso não apenas em razão de seu caráter teórico. Quanto ao relativismo cultural 
sem restrição, ele desemboca na visão de qualquer cultura como um absoluto, não admitindo crítica ou contestação alguma sobre qualquer cultura. Imprecisões a respeito desse ponto podem ser consideradas responsáveis por muitos mal-entendidos nas discussões atuais. Para começar, é preciso, todavia, saber em que consiste a perspectiva principal de uma teoria dos direitos humanos: ela se esforça em determinar critérios de valores concretos, práticos e racionais e não somente em estabelecer um inventário dos valores, reconhecidos em cada cultura, que se aplicariam unicamente porque tais culturas são admitidas de facto.

Para uma sociedade, os critérios chamados direitos humanos são normalmente definidos no bojo de um sistema jurídico (legislação ou direito costumeiro). A idéia de correlação entre o regime jurídico e o estado de desenvolvimento correspondente é justa. De acordo com a análise unilateral freqüentemente aplicada aos problemas do Terceiro Mundo, o conjunto das estruturas jurídicas de um país é determinado por seu nível de desenvolvimento e integração; entretanto, para além disso, conviria examinar também seu inverso: graças à sua maneira de estruturar a proteção dos direitos fundamentais, um regime jurídico influi sobre o nível de desenvolvimento e de integração do país.

As considerações sobre a universalidade dos direitos humanos apresentam longa tradição na filosofia do direito, sobretudo na filosofia moderna do direito natural, na teoria positivista referente ao direito subjetivo, assim como na jurisprudência moderna que se esforça gradualmente para englobar a instituição dos direitos humanos no interior do sistema das noções jurídicas e na sua aplicação prática.

O progresso na elaboração dessa questão dependia sempre da maneira pela qual a filosofia e a teoria jurídicas conseguiam resolver os problemas fundamentais da matéria, sobretudo os que diziam respeito à noção de direito e suas fontes, à relação entre ele e a justiça, ou mesmo à moral, ao fator subjetivo e ao fator objetivo no domínio do direito, ao papel do Estado na sua formação e à relação entre o direito e a sociedade em geral (6).

Os esforços que tendem a essa integração metodológica se manifestam não somente na filosofia e na teoria do direito ocidentais, mas igualmente nas tendências marxistas.

A universalidade dos direitos humanos é, então, a manifestação fundamental de seu caráter objetivo. Essa aparente atitude científica nos domínios de sua doutrina nunca se manifestou sob forma pura, tendo encontrado, no entanto, muitos defensores durante cada período sucessivo e eram seus partidários que determinavam a orientação das pesquisas a serem feitas (7). As diversas concepções dos direitos humanos, como a democrática e a utilitarista, a teoria baseada no conceito de Estado de direito (Rechsstaat), a concepção ético-humanitária e civilizadora etc., que tratam sobretudo do lado funcional de tais direitos, contribuem indiretamente para o estudo de sua base objetiva.

A noção de direitos humanos constitui ao mesmo tempo a obra evidenciada do pensamento filosófico e teórico; é aí, inclusive, que pode existir sob forma pura 
e original, aliás a mais valorizada na cultura jurídica moderna, diferentemente das legislações que nem sempre aceitavam a noção de direitos humanos, a não ser com certos limites e num sentido modificado, sob forma dos direitos fundamentais ou até cívicos.

A concepção histórica dos direitos humanos é compatível com a que se baseia no direito natural, à medida em que pode implicar a noção de homem universal e, também, de mínimo de direitos básicos ligados às novas possibilidades que o desenvolvimento da sociedade moderna cria para qualquer indivíduo. Aliás, a maior querela teórica jamais consistia na negação ou na defesa da variabilidade histórica do estatuto dos direitos humanos, mas, ao contrário, na questão de saber se existe ou não um limite extremo, um mínimo inalienável da situação autônoma do indivíduo, sem o que são impensáveis tanto a vida do homem individual quanto a coexistência social. Nesse sentido, a universalidade dos direitos humanos deve ser compreendida de modo absoluto, caso sua idéia não deva ser arbitrariamente adaptada, ou mesmo negada por inteiro, nos diversos países, conforme evolua a apreciação da situação histórica concreta.

Hoje em dia, na época do Estado dito social, a evolução tende ao estatuto dito positivo (ativo), no qual o Estado intervém na esfera econômica e social e, mesmo, os métodos próprios ao direito público adentram a esfera do direito privado

A tendência positivista da ciência do direito de transpor a idéia teórica dos direitos naturais individuais para as categorias do direito em vigor, expresso presentemente sobretudo por leis, preparou já o terreno para o positivismo jurídico do século XIX que não reconhece a noção dos direitos humanos a não ser sob a forma da regulamentação aplicável.

\section{A universalidade dos direitos humanos}

Falar da universalidade de tais direitos numa época em que são universalmente violados pode apresentar um caráter desafiador. Ora, no plano dos princípios, todos os homens podem invocar os mesmos direitos e todos os poderes políticos devem perseguir fins humanos, caso nos atenhamos, ao menos, à leitura dos múltiplos instrumentos internacionais que regulamentam o campo dos direitos em questão e o aproximam em suas duas direções; pois, enfim, não se deve esquecer que qualquer problema relativo a eles faz surgir uma relação vertical e outra lateral.

A vertical é a do cidadão face ao poder, isto é, os direitos humanos concebidos como protesto, reivindicação. Há, entretanto, uma relação lateral que lembra um esforço de solidariedade, cooperação. Essas duas relações reencontram-se no direito internacional dos direitos humanos e pode-se dizer sumariamente que a relação vertical marca o lugar dos direitos civis e políticos, os quais dizem respeito às relações entre o cidadão e o poder; a relação lateral coloca em evidência os direitos econômicos e sociais que, na ordem interna, exigem do Estado, ou seja, por meio dele, contribuições em favor dos menos favorecidos feitas pelos cidadãos mais aquinhoados e, na ordem internacional, a ajuda dos países ricos àqueles em desenvolvimento com base em uma obrigação jurídica. 
O problema das relações entre a comunidade e o indivíduo existe para todos os países, quer sejam desenvolvidos ou não. É evidente que o desenvolvimento permite o exercício mais completo dos direitos humanos. Enquanto a miséria reinar, muitos deles constituirão ilusões. Tal fato já foi afirmado, em 1968, na Conferência de Teerã sobre o assunto e acabou de ser dito em Viena, em 1993, na Conferência das Nações Unidas sobre o tema. O desenvolvimento é, portanto, condição para uma realização cada vez mais completa dos direitos em tela. No entanto, daí a dizer, como alguns, que se trata de elemento preliminar, é outra história. Na realidade, o direito ao desenvolvimento e os direitos humanos, como algo individual, não são contraditórios. É preciso distinguir entre o direito ao desenvolvimento como direito dos povos e o mesmo direito como pertencente ao homem. Ambos devem ser igualmente afirmados.

O direito dos povos ao desenvolvimento é fundamental. Baseia-se em solidariedade expressa no conceito de comunidade internacional. Tal conceito justifica o fato de os deveres fazerem parte dos encargos dos países industriais, em benefício dos países pobres, que, desse modo, podem invocar direitos e não pedir esmolas. Se não existisse comunidade internacional, os países industriais poderiam sempre responder aos em vias de desenvolvimento: "Só os conheceremos quando concluirmos um tratado; não temos nenhum laço jurídico, não lhes devemos nada". É precisamente a idéia de comunidade internacional que exprime a obrigação de solidariedade e faz recair sobre os ricos encargos em favor dos pobres, mesmo que não tenham sido celebrados tratados. Disso nasce todo um feixe de princípios gerais de direito que têm como fundamento a idéia de comunidade internacional, como aliás reconheceu a Corte Internacional de Justiça de Haia, no parágrafo 34 da decisão sobre a Barcelona Traction Company.

Por outro lado, existe também um direito do homem ao desenvolvimento, cuja resolução foi proclamada, em 1986, nas Nações Unidas. É indispensável afirmálo. Apenas afirmar o direito dos povos nesse momento é correr o risco de ver o direito dos povos ao desenvolvimento não ter como preocupação uma finalidade humana. É o direito do homem ao desenvolvimento que dá tal finalidade aos direitos do povo. A utilidade da afirmação do direito do indivíduo ao desenvolvimento está em que este não seja conduzido de modo a desprezar o ser humano e, em vista disso, vemos surgir uma relação dialética entre a comunidade e o indivíduo.

Não se poderia afirmar o indivíduo, desconhecendo-se a comunidade; não se poderia desconhecê-lo, afirmando-se a comunidade. É preciso afirmar a comunidade sem a qual o indivíduo é um ser irresponsável; é o burguês do século XIX, orgulhoso de seus direitos humanos, mas egocêntrico, concentrado nos seus direitos como num capital, ignorando o dos outros, mas deve se afirmar o indivíduo, sem o qual a comunidade se torna uma abstração opressiva, até mesmo destruidora. Ora, o direito internacional dos direitos humanos tem como objeto assegurar tal integração para além das disparidades ideológicas e de desenvolvimento. Quer assegurá-la pela afirmação de normas comuns, algo que chamamos integração normativa, situada em dois níveis: no da formulação das normas e no da realização delas. 
No plano da formulação, vemos surgirem métodos radicais, como os que consistem, de um lado, em afirmar que as normas dos direitos humanos terão um efeito absoluto, válido em relação a todos, erga omnes, consistindo, portanto, em rejeitar a regra clássica em direito internacional do efeito relativo dos tratados. Certas convenções, sobretudo as da Organização Internacional do Trabalho, têm efeito erga omnes. Por outro lado, recorre-se freqüentemente à proibição das restrições. Muitas convenções em matéria dos direitos em questão (penso nas convenções da Unesco, nas da OIT) pró́bem a formulação de restrições, no intuito de aumentar a universalidade de seu alcance

Se passarmos ao plano da colocação, no lugar da realização dos direitos, encontraremos aí ainda métodos, regras adotadas. Primeiramente, lembrarei o fato de que o princípio da reciprocidade sobre o qual se funda todo o direito internacional clássico está afastado. Há o desejo de se criar, por meio das convenções que afirmam os direitos humanos, uma ordem jurídica objetiva ou, segundo a Comissão Européia dos Direitos Humanos, uma ordem jurídica comunitária, ou seja, não nos encontramos diante de um sistema de natureza contratual. Um Estado não pode subordinar seu respeito a tais direitos ao respeito dos mesmos pelo seu parceiro de contrato. Não se regateia com os direitos humanos. Não estamos diante do do ut des. Trata-se de ordem jurídica objetiva, uma mesma legalidade para todos. Eis por que o princípio consensualista, contratualista da reciprocidade se acha afastado no que diz respeito ao próprio homem.

Em segundo lugar, o que também impressiona, é a larga abertura dos recursos. Quando existem, seja perante organismos políticos ou órgãos técnicos, judiciários ou para-judiciários, ficamos impressionados com sua extraordinária abertura que quase confina com a noção de actio popularis (8).

Tanto na história do mundo moderno, quanto no campo das lutas de emancipação, gênese e evolução dos direitos do homem e dos povos, podemos reter - provisoriamente é verdade - datas importantes como 1688, 1776, 1789, 1917, 1945, 1960 ... Elas marcam, cronologicamente, The Glorious Revolution na Inglaterra, a Declaração da Independência dos Estados Unidos da América, a Revolução Francesa, a Revolução Socialista Russa, a Proclamação da República Popular da China e o Advento das Independências dos povos coloniais. Desde então, no entanto, os direitos humanos e os dos Povos permaneceram como conceitos distintos, malgrado o entrecruzamento de seus fios. Não se poderia tratar de os opor, como por vezes se faz, sendo preferível analisar um em relação ao outro, estudar em que convergem, se são, inclusive, complementares e de que modo, em seus planos respectivos, a elaboração conceitual foi progressiva. Além disso, cabe buscar o que constitui obstáculo à sua execução.

\section{Universalidade dos direitos humanos e sua relação com a democracia social}

Com a adoção e a aceitação da Carta das Nações Unidas, da Declaração Universal dos Direitos do Homem e de instrumentos internacionais posteriores no domínio dos direitos humanos, reconheceu-se o princípio de que cada um tem 
direito à dignidade e ao respeito, a ser reconhecido em qualquer lugar como pessoa diante da lei, assim como ninguém pode ser excluído das vantagens do direito e da justiça. Tal reconhecimento representa uma ruptura fundamental com um passado no qual os Direitos Humanos só evocavam os dos privilegiados. É significativo que, em várias sociedades, o direito de participar do governo e o de possuir bens foram por muito tempo privilégio e domínio exclusivo de limitadas categorias de pessoas. As relações humanas - em nível nacional e internacional - tanto em base individual quanto coletiva, consistiam freqüentemente em relações semelhantes às de bens materiais e mercadorias. A história das relações humanas relata numerosos exemplos de pessoas, cujas vidas foram sacrificadas impunemente, tendo sido submetidas a todos os tipos de tratamentos cruéis, desumanos ou degradantes. A história da humanidade está repleta de desumanidade do homem para com o homem e de injustiças das nações para com outras nações. Considerando tais fatos e, em particular, reagindo em face dos crimes contra a humanidade cometidos ao longo da Segunda Guerra Mundial, o Preâmbulo da Declaração Universal dos Direitos do Homem verificava que o "desconhecimento e o desprezo dos direitos humanos conduziram a atos de barbárie que revoltam a consciência da humanidade e que o advento de um mundo no qual os seres humanos serão livres para falar e crer, libertados do terror e da miséria, foi proclamado como a mais alta aspiração do homem" (9).

Tal universalidade dos direitos humanos fundamenta-se nas premissas da igualdade em dignidade e valor de todos os seres humanos, sem discriminação. Tal noção é totalmente incompatível com as doutrinas e práticas de uma pretensa superioridade fundada em raça, religião, sexo ou qualquer outro elemento. A universalidade dos direitos implica também que a humanidade reconhece os valores comuns e as nações têm direitos essenciais à sua própria existência e à sua identidade, as quais fazem parte do patrimônio comum da humanidade. A universalidade, a dignidade, a identidade e a não-discriminação são conceitos centrais em matéria de direitos humanos, à medida em que se aplicam a todos os campos.

Geralmente reconhece-se, por um lado, que os direitos civis e políticos, por outro, os direitos econômicos, sociais e culturais, constituem um conjunto de valor essencial para a manutenção da dignidade, da liberdade e do bem-estar dos homens. A indivisibilidade e a interdependência de tais direitos foram confirmadas em várias ocasiões e, muito recentemente, na Declaração sobre o direito ao desenvolvimento: "Todos os direitos humanos e todas as liberdades fundamentais são indivisíveis e interdependentes; a realização, a promoção e a proteção dos direitos civis, políticos, econômicos, sociais e culturais devem se beneficiar de uma atenção igual e ser encaradas com uma urgência igual" (10).

É lamentável que, no seio dos debates ideológicos, sejam demasiadamente enfatizadas as supostas contradições entre essas duas categorias de direitos (11). Tanto os direitos políticos quanto os sociais são elementos de uma sociedade na qual a liberdade política e a justiça social representam valores predominantes. Tal sociedade une a democracia política à social. É igualmente o tipo de sociedade que protege o fraco, o vulnerável e considera as exigências da solidariedade como 
integrante de sua vida constitucional e social, tendo o mesmo valor das prescrições políticas da democracia. Queremos, igualmente, evidenciar dois aspectos do direito à autodeterminação. Em primeiro lugar, sua importância para os direitos humanos em geral; em segundo, seu caráter de princípio democrático.

No que tange à importância do direito à autodeterminação com relação aos direitos humanos em geral, tem-se observado, com justa razão, que sua realização é uma "condição essencial de garantia e de aplicação efetiva dos direitos do indivíduo e de seu reforço" (12).

Desse modo, o direito à autodeterminação é um princípio democrático. Todos sabem que a dominação estrangeira constitui uma negação desse direito em suas dimensões internacionais, mas queremos também chamar a atenção sobre algo que foi chamado de aspectos internos do direito à autodeterminação (13). Tal direito abarca, nesse caso, o conceito central de democracia, de modo que "a vontade do povo é o fundamento da autoridade do poder público" (14). Mais precisamente em suas dimensões internas e como princípio democrático, está igualmente ligado ao artigo 25 do Pacto Internacional relativo aos Direitos Civis e Políticos, que reivindica o direito e a possibilidade para todos os cidadãos, de tomar parte na direção da coisa pública, seja diretamente ou por intermédio de representantes livremente escolhidos (15).

Por mais que eleições livres sejam importantes como condição da realização de um regime democrático, não são suficientes por si mesmas e não garantem os direitos humanos nem a democracia (16).

Muitas situações nacionais, assim como regimes políticos em todo o mundo, são praticamente apenas democracias fantasmas. Em suas constituições e instituições políticas, os acessórios da democracia só funcionam como fachada. Largos setores da população não têm participação alguma na vida política. Do mesmo modo, a qualidade da democracia fica em perigo nas sociedades que mantêm desigualdades gritantes em detrimento dos pobres, desfavorecidos e marginalizados. A democracia política sem a social ignora os laços entre democracia, solidariedade e direitos humanos (17).

Um dos problemas-chave, no conflito que opõe os poderes às elites críticas, é a tolerância ou a não-tolerância com relação aos comportamentos cujos sistemas de valores não são compatíveis.

A intolerância talvez esteja profundamente enraizada no comportamento humano, pois o homem parece ter uma atitude inata de altruísmo e solidariedade, mas que é, em geral, de alcance limitado e não recobre - pelo menos na mesma medida - a humanidade inteira. Em contrapartida, a tolerância parece ser um produto sutil da história cultural, ligada a certas condições políticas. A intolerância metateórica, entretanto, representa um perigo particular que as ideologias e religiões no poder com freqüência não querem abandonar - pretextando que sua concepção do mundo é a única a garantir a salvação e considerando os outros sistemas políticos e sociais votados ao fracasso. Assim, as elites dirigentes têm um interesse particular em impor, no seu território, a teoria da incompatibilidade dos 
sistemas e da superioridade da sua, por meio de um grupo de funcionários submetidos ao regime no poder. Com muita freqüência, a população mostra-se indiferente a essa querela, preocupando-se mais com suas próprias condições de vida.

Há, sem dúvida, limites de tolerância, pois a coabitação humana exige outrossim certa medida de consenso; é assim que, também nesse caso, descobrimos aspectos metateóricos, com a possibilidade de a consciência de si mesmo se manifestar em diferentes níveis, chegando mesmo à justificação de certo racismo, fonte de conflitos.

Acabo assim de fazer a síntese das três gerações dos direitos humanos tornadas clássicas: a primeira, concernente aos direitos civis e políticos, dominada pela tradição e pela civilização ocidentais; a segunda, que é a dos direitos econômicos, sociais e culturais, cuja emergência se dá com as revoluções russa e mexicana; a terceira, a dos direitos dos povos ou de solidariedade, refere-se ao direito à autodeterminação, à paz, ao desenvolvimento, ao meio ambiente e à informação que só pode se realizar por meio de um esforço solidário entre os diferentes atores individuais e coletivos, tanto no plano nacional quanto no internacional.

É preciso desde logo anunciar, com vigor, a necessidade de uma pesquisa em profundidade com vistas à promoção de uma nova geração - a quarta - que seria, no nosso entender, a dos direitos à democracia, às comunicações e aos pluralismos cujos beneficiários serão os indivíduos, as comunidades e os povos. Em caso de sua violação, sanções conseqüentes e correspondentes deverão ser aplicadas para terminar, desse modo, com o infeliz costume da impunidade.

\section{A democracia, um direito fundamental de quarta geração?}

Mais do que um sistema de governo, uma modalidade de Estado, um regime político ou uma forma de vida, a democracia, nesse fim de século, tende a se tornar, ou já se tornou, o mais recente direito dos povos e dos cidadãos. É um direito de qualidade distinta, de quarta geração.

No consenso dos publicistas, direitos de primeira geração foram os individuais; de segunda geração, os econômicos, sociais, culturais e, em último lugar, na era da tecnologia, direitos de terceira geração, entendidos como a paz, o desenvolvimento, o interesse dos consumidores, a qualidade de vida e a liberdade de informação. As três gerações são regidas ou inspiradas sucessiva e cumulativamente pelos princípios de liberdade, igualdade e solidariedade.

O caráter jurídico da democracia começa já a se exteriorizar positivamente em termos da transparência manifesta nos atos coletivos de intervenção da ONU; na formação de uma polícia ou um exército que se exercita ou é susceptível de agir universalmente em nome da paz, nas situações concretas de crise, como na África ou na Iugoslávia, paz cujo sentido político não pode ser outro senão o de sua identidade com a democracia como valor positivo universal. 
A democracia é, desse modo, o princípio contemporâneo pelo qual a legitimidade é conferida a todas as formas possíveis de relações; poder-se-ia mesmo dizer o único princípio que legitima a cidadania e a internacionalidade. Foi o princípio filosófico das revoluções: é jurídico nas elaborações pacíficas de cada sistema de governo que deve reger os cidadãos ou dirigir os Estados em suas relações mútuas. Do ponto de vista interno, a democracia torna legítimo o direito de resistência à opressão; do ponto de vista externo, ela torna lícita a intervenção militar de uma ordem supranacional gradualmente esboçada e efetivada. Em seu nome, a intervenção procura apear do poder as ditaduras do absolutismo e banir os regimes opostos à democracia e, por essa razão, declarados fora da lei, a lei que governará os povos e as nações. Conceitual ou positivamente, a democracia é um princípio e os princípios têm sua normatividade já definida e reconhecida em certas ordens institucionais.

Transformando em direito fundamental, o mais fundamental dos direitos políticos, repetimos, de quarta geração, para assinalar o teor da novidade de sua aplicação obrigatória, a democracia não é unicamente o direito natural das declarações universais, políticas e filosóficas, dos séculos revolucionários, mas também o direito positivo das Constituições e dos tratados e, portanto, de observância necessária à vida tanto interna quanto externa dos Estados (18).

Esse direito compõe, assim, o caráter novo da civilização política, que desde já marca o advento do terceiro milênio. Sendo, necessariamente, um direito fundamental - e partimos dessa premissa, cujo argumento mais persuasivo é a impossibilidade factual da igualdade e da justiça fora de tal esfera de compreensão - não há dúvida de que para o poder positivar em cada ordenação jurídica, é preciso estabelecê-lo sob a forma de democracia direta. Uma democracia concebida de maneira substantiva, erigida em princípio cardeal inspirador de qualquer organização participativa da cidadania, com liberdade, consenso e pluralismo (19).

Eis como podemos justificar tacitamente a democracia como direito fundamental de quarta geração. Direito que não é possível, em nossa opinião, a não ser que, na ordem interna, venhamos a instituir um novo conceito de democracia direta.

É importante e essencial, ou mesmo indispensável, para definir hoje em dia a identidade da democracia direta, que o povo tenha imediatamente à sua disposição, para o exercício de uma participação fácil e efetiva, instrumentos de seu controle. Sem isso, a participação será sempre ilusória e ela o é no que chamamos de democracias representativas do Terceiro Mundo, onde tais instrumentos compõem freqüentemente o anteparo no qual se escondem muito assiduamente as mais servis ditaduras sociais de açambarcamento da liberdade humana.

Esse controle deverá se estender tanto ao campo institucional quanto à mais alta esfera de responsabilidade de governo e se propagar a todos os ramos da administração, de tal modo que não se possa, em momento algum, contestar ou abalar a legitimidade dos atos capitais do exercício da autoridade pública.

Temos aí uma participação direta do povo, segura e eficaz no campo da decisão, que não é simplesmente formal e adjetiva mas incontestavelmente provida 
de substância e conteúdo. É por aí que passa, reconhecida e sem refutação, a soberania do povo em toda sua majestade e plenitude.

Dito de outro modo, para formular o conceito de democracia direta, a condição preliminar de eliminação completa das formas representativas não é indispensável. A coexistência eventual dessas últimas com mecanismos como a iniciativa popular, o plebiscito, o referendo, o veto e o direito de derrogação não destrói, não desfigura, não a faz perder seu caráter nem a invalida.

Passo, assim, ao último ponto de minha comunicação para tecer breves comentários sobre a democracia como direito e condição do desenvolvimento e da paz social na África.

\section{A democracia e o desenvolvimento da África}

Todos os observadores africanos e estrangeiros descrevem a situação social e econômica da África em termos de um continente totalmente arruinado e egresso de uma guerra. Com efeito, a África atravessa três grandes guerras sucessivas que duram há séculos.

A primeira, é a do tráfico negreiro, durante a qual a África conhecia uma lenta evolução de suas sociedades que, no século X, tinham atingido um nível comparável, em muitos pontos, ao das sociedades ocidentais. Reinados e impérios centralizados, às vezes tão vastos quanto a França, e cujo refinamento da produção artística é testemunha de um nível que, desde então, nunca mais atingimos. A irrupção do tráfico, além dos danos do ponto de vista populacional, provocou duas conseqüências maiores: de um lado, a parada brusca da evolução material dessas sociedades e, de outro, a aparição de novo tipo de poder, o do rei negreiro, proprietário do país, das riquezas e das população que ele vendia aos comerciantes de escravos. Isto foi uma catástrofe sócio-política de amplidão tal que as regiões afetadas pelo tráfico não somente se esvaziavam de suas populações, como também não possuíam mais cultura própria que permitisse a retomada da evolução social, donde uma forte regressão em relação às nossas sociedade não afetadas pelo tráfico.

Ao sair dessa desastrosa catástrofe, veio a segunda guerra sob a forma de colonização européia. Dessa vez, não se tratava de guerra do tipo clássico ou de semelhança com o tráfico, que afetava a população em sua sobrevivência. Foi, no entanto, um desastre do ponto de vista das culturas africanas. As sociedades, chefferies (20), reinados e impérios eram organizados de maneira a colocar o bem do indivíduo-membro no centro das preocupações políticas. Tratava-se de sociedades solidárias com a preocupação de que ninguém fosse nem pior nem melhor que a média da população A irrupção da Europa mudou fundamentalmente essa distribuição. O Estado existe por e para si mesmo, desigualdades tornam-se concebíveis e aceitáveis. A solidariedade desaparece. Ainda mais: os limites de tais sociedades se vêem estendidos a países sem medida comum com os territórios tribais. É a guerra inaugurada pelo pacto colonial nascido na Conferência de Berlim de 18841885, há 110 anos. Pior ainda, a introdução da moeda como unidade de medida do valor das coisas subverteu completamente nossa relação com as coisas. A partir 
daí, tudo era mensurável com base no dinheiro e, portanto, comerciável. Nada mais era sagrado e intocável: o homem, a consciência, o trabalho, o pensamento, a gentileza tudo tornava-se mercadoria, portanto, comerciável.

Tendo saído manietados do tráfico e da colonização, os africanos vêm a conhecer a independência dos anos 60 , a qual não consegue coabitar com as estruturas coloniais recém-instituídas, nem dentro das mesmas; assim sobreveio a terceira guerra: a irrupção das ditaduras sangüinárias, do poder do tipo negreiro como proprietários de nossos países, suas riquezas e nossas vidas. Os africanos estão prontos a pagar o preço dessa guerra que visa à democracia, mas correm o risco de ele ser elevado demais, em vista da simpatia antinatural que as democracias ocidentais ainda têm por certas ditaduras africanas (21).

\section{Democracia como direito e condição do desenvolvimento da paz social (22)}

$\mathrm{Na}$ África, a luta pela democracia encontra sua justificação integral na determinação do povo em recuperar a liberdade, a independência de seus territórios pré-coloniais e a dignidade racial que o imperialismo, o colonialismo e o racismo the arrancaram. Permitindo a alternância dos regimes e protegendo a existência dos contrapoderes, a democracia é a primeira muralha contra a corrupção e a arbitrariedade dos dirigentes.

É também um estado de espírito, uma questão de consenso internacional, uma procura permanente que deve ignorar fronteiras, raças e culturas. Deve ser busca de verdade, defesa dos direitos universais do homem, responsabilização crescente do cidadão face aos desafios do desenvolvimento, que a África tem obrigação de recuperar.

A instauração de um sistema democrático exigirá a eliminação de considerável número de barreiras estruturais e institucionais que constituem obstáculos à participação da população. Para os camponeses e as camadas desfavorecidas da cidade, as grandes questões que se colocam são as do controle do aparelho do Estado e dos organismos de comercialização; da posse da terra e do capital; do controle dos meios de comunicação, das discussões, das assembléias. Uma transferência do poder de decisão para o nível das coletividades locais será impossível sem reformas penosas da administração e do sistema de propriedade fundiária.

A democracia sem o desenvolvimento é como uma viagem em um túnel sem saída. Se a democracia e o desenvolvimento condicionam-se mutuamente, é forçoso verificar que os programas de ajustamento estrutural impostos do exterior, com todas as suas conseqüências sociais, colocam a democratização na África diante de um enorme dilema.

Os que sonham com uma melhoria imediata de suas condições de vida só podem seguir a contragosto os apelos permanentes para novas privações. As medidas de austeridade que prioritariamente atingem os mais desprovidos são um humo democrático bastante ruim. As numerosas greves que se desencadearam na África em mutação ilustram tal estado de coisas. 
A passagem atual das ruínas do Estado pós-colonial para o alicerce ainda oscilante do Estado de direito é por natureza um período de conflitos políticos, econômicos, sociais e culturais durante o qual o multipartidarismo não constitui uma fórmula miraculosa. Não bastará introduzir o pluralismo para afastar definitivamente o perigo de regimes autocráticos. Também não bastará mudar os dirigentes para instaurar a democracia. Será importante, antes de tudo, traduzir, por meio de fatos, uma democracia política baseada na idéia de participação, nas liberdades políticas fundamentais, assim como o Estado de direito e os direitos econômicos e sociais. A democracia só poderá triunfar caso se apóie numa cultura política correspondente.

Esperar da democratização política uma melhoria fundamental da situação econômica também seria ilusório. É trágico que, na sua fase atual, a África receba do exterior uma ajuda inferior à que obtinha quando servia apenas de tabuleiro de xadrez para as grandes potências. Que aqueles que hoje recusam uma ajuda maciça e orientada ao processo de democratização não se deixem levar, amanhã, pela tentação de colocar a África no banco dos réus, denunciando sua incapacidade democrática! A sobrevivência de sua democracia está irrevogavelmente ligada à instauração do equilíbrio nas relações comerciais internacionais.

Os democratas africanos, os que querem realmente mudar o sistema, têm necessidade de maior solidariedade por parte do exterior, traduzida por apoio concreto e orientado. O objetivo dessa solidariedade internacional deve se traduzir no plano nacional por uma repartição mais eqüitativa dos bens no interior de cada país, cuja ordem econômica não pode estar fundada na persistência de privilégios econômicos e sociais de certa classe, seja ela étnica ou burocrática.

\section{Conclusão}

$\mathrm{Na}$ África, é sobretudo no plano dos valores morais que a transição para a democracia deverá ser conquistada. Impõe-se uma transformação radical das mentalidades, para extirpar os antivalores e os comportamentos nefastos desenvolvidos durante décadas, durante as quais a corrupção, o gosto pelos bens mal-adquiridos e a negligência foram tomados como modo de funcionamento do Estado.

A democracia não será um presente concedido numa salva de prata. Assim como a independência, ela deve ser conquistada. E face à feroz resistência das forças do status quo, a democracia só pode se realizar graças à vontade e às lutas populares. De resto, ela é o resultado de tais lutas, uma conquista do povo apaixonado pela liberdade e comprometido a realizar suas aspirações de uma vida melhor, apesar de todos os obstáculos e acidentes de percurso.

Como valor universal, ela é buscada por todos os povos, pois é um bem, um valor da natural e inalienável vocação humana de tomar a si o encargo do destino individual e coletivo. É um desejo inextinguível de liberdade e uma aspiração insaciável do melhor.

Como exigência moral, ela surge no homem e no seio do próprio povo concernido. É um fator indispensável do progresso que está ligado a certo grau de 
liberalismo e, à medida em que tal corrente de pensamento considera ser o indivíduo uma fonte insubstituível de invenção e criação, torna-se um motor essencial do progresso material e moral. A pessoa humana é o motor do progresso; para isso, precisa de motivações que se encontram no proveito (não necessariamente mercantil) que uma empreitada lhe assegura. Na medida que a pessoa se vê como fim e não simplesmente como meio ela consente em participar de uma ação.

O desenvolvimento da África exige que os déficits alimentares sejam cobertos, no menor prazo, por meio do crescimento substancial, sustentado e igualitário da produção agrícola que, por si só, pode permitir a elevação do nível de vida do maior número pessoas e o crescimento estável dos mercados internos. Tal crescimento requer as reestruturações fundiárias indispensáveis e a participação ativa das comunidades de base.

O desenvolvimento repousa também sobre a criatividade e implica sistema de educação e formação que a estimulam; a valorização do potencial de conhecimentos científicos e técnicos de produtores, em particular das mulheres; a utilização apropriada das tecnologias de ponta e a apropriação das técnicas pelos interessados.

Nas circunstâncias atuais, o desenvolvimento da África não pode resultar de uma integração mais estreita à economia mundial, sobretudo porque suas novas tendências contribuem para desvalorizar cada vez mais os recursos humanos e naturais do continente africano e, por isso mesmo, a marginalizá-lo. Ao contrário, os países africanos devem procurar, no próprio continente e entre eles mesmos, os caminhos e os meios de cooperação para seu desenvolvimento.

A luta pelos direitos humanos tomou formas muito diversas, em sintonia com as culturas históricas e os sistemas jurídicos.

Se a liberdade, a dignidade e a justiça são valores universais, são entretanto interpretadas por cada Estado em disposições legislativas que estão em relação direita com as contradições internas e a política interior desse Estado.

A concepção histórica, que atualmente é muito difundida, estabelece conexão entre a origem da idéia de direitos humanos e a crise da sociedade medieval, quando então as circunstâncias da época começaram a impelir para o primeiro plano a personalidade do indivíduo, não somente na esfera do direito privado, mas igualmente em face do Estado e dos representantes do poder econômico.

A concepção histórica é, nesse sentido, simplista, incompleta e concentrase na questão da realização dos direitos humanos e não sobre a própria noção; só a aceita como um fenômeno que surgiu em certo grau do desenvolvimento histórico.

Se as idéias jurídicas da Antigüidade e da Idade Média dão corpo em suma à noção de direito, tal como esta se estabilizou ao longo do período histórico mais recente, ou se possuem ao menos uma forma rudimentar correspondente ao direito moderno, o problema dos direitos humanos deve ser, de um modo ou de outro, englobado na antiga concepção do direito. 
A filosofia do direito da Antigüidade e, mais tarde, a doutrina tomista muito fizeram em favor da determinação da base objetiva do direito e em favor da abolição do subjetivismo e dos métodos simplistas aplicados à pesquisa, sendo certo, também, que aquela filosofia criou as primeiras condições econômicas, políticas e morais na sociedade de antanho.

O direito natural evidentemente não possui sanção direta assegurada pelo Estado, não é suficientemente imperativo, de modo que seu alcance prático fica em larga medida enfraquecido, sendo ele, por essa razão, freqüentemente comparado às influências exercidas pela moral. Entretanto, conta indiretamente com a sanção assegurada pelo Estado, cuja forma jurídica é determinada pela construção do contrato social. A ciência jurídica elabora noções que tornam realidade a superioridade do direito natural racionalista, nos limites do direito positivo, livrando assim o dualismo original do direito natural e do positivo de seus antagonismos interiores.

Em sociedades complexas, como a internacional, as instituições políticas e jurídicas emanadas de condições econômicas e sociais são meios pelos quais se pode procurar melhorar a satisfação das necessidades. Não há, obrigatoriamente, correspondência direta entre um direito e cada necessidade, mas pode ser afirmado que a consagração de uma necessidade em termos jurídicos intervém quando a demanda de satisfação é particularmente intensa.

Um direito humano foi definido como aquele cujo caráter, considerado fundamental para todos os seres, é proclamado ou reconhecido como tal por um órgão competente.

Os compromissos internacionais dos Estados, no campo dos direitos humanos, permitem, outrossim, legitimar reivindicações que emanam de indivíduos e grupos. Todavia, não se deve perder de vista a dupla ambigüidade que se esconde atrás da formulação atual dos direitos humanos no plano internacional; é o resultado de compromissos realizados por representantes de ideologias diferentes e contraditórias.

As considerações sobre a universalidade na teoria dos direitos humanos têm uma longa tradição na filosofia moderna do direito natural e na teoria positivista do direito imperativo, mas também na atual jurisprudência que tende a incluir as instituições dos direitos humanos no sistema das noções de direito e sua aplicação na prática. A adoção da Declaração Universal dos Direitos do Homem pelas Nações Unidas representa o primeiro esforço desenvolvido para encorajar e apoiar uma codificação internacional do conceito que os coloca como direitos universais.

Notas

1 Van Boven, Théo. Texto da aula pública dada em Louvain-la-Neuve, em 7 de dezembro de 1982, por ocasião do recebimento do título de Doutor Honoris Causa da Universidade Católica de Louvain. 
2 Asborne Eide. Documento de trabalho Les droits civils et politiques-35 ans après. Genebra, 1984.

3 Szabo I. Fondements historiques et développement des droits de l'homme, in les dimensions intern. Des droits de l'homme. Manual destinado ao ensino dos direitos humanos nas Universidades. Paris, Unesco, 1978, p.11.

4 Eze Osita C. Les droits de l'homme et le sous-développement. Paris, Revue des Droits de l'Homme. v. XII, n. 1-2, p. 16, 1979.

5 Fasil, Nahun. African contribution to human rights. Contribuição ao SEMINAR ON LAW AND HUMAN RIGHTS IN DEVELOPMENT, Gaborone, Botswana, 24-28 de maio de 1982.

6 Veverka V. La question de l'universalisme dans la théorie des droits de l'homme, p. 9-30.

7 Um dos teóricos contemporâneos dos direitos humanos e do cidadão - G. Burdeau atribui, por exemplo, papel considerável ao método sociológico (cf. Paris, Libertés publiques, 1961).

8 Dupuy, R.J. L'universalité des droits de l'homme. Discurso na abertura dos cursos de verão. Estrasburgo, Instituto Internacional dos Direitos Humanos, 1984.

9 Van Boven, Théo C. Démocratie, droits de l'homme et solidarieté. Comunicação aO COLÓQUIO DO CONSELHO DA EUROPA SOBRE DÉMOCRATIE ET DROITS DE L'HOMME, Tessalônica, Grécia, 24-26 de setembro de 1987.

10 Artigo 6, parágrafo $2^{\circ}$.

11 Ver introdução às relações nacionais sobre a aplicação dos Direitos Humanos, pelo Ministério das Relações Estrangeiras dos Estados-Unidos. Washington, Departamento de Estado, fev. 1986, p.2.

12 Observações gerais da Comissão dos Direitos Humanos sobre o artigo 40, parágrafo $4^{\circ}$, do Pacto Internacional relativo aos Direitos Civis e Políticos. Observação geral n. 12 , art. $1^{\circ}$.

13 Cassese, Antonio. Political self-determination. Old concepts and new developments. In: Cassese, A. (ed.), UN law/fundamental rights. 1979, p.137-165; Alexandre Kiss. The people's right to self-determination. Human Rights Law Journal, v. 7, p.165$175,1986$.

14 Artigo 21, parágrafo $3^{\circ}$ da Declaração Universal dos Direitos do Homem.

15 Ver o primeiro Protocolo da Convenção Européia de Salvaguarda dos Direitos Humanos e das Liberdades Fundamentais, artigo $3^{\circ}$.

16 Ver, no mesmo sentido, a Resolução 800 (1983) da Assembléia Consultiva do Conselho da Europa, parte B.

17 Jacot-Guillarmod, M.O. Rapports entre démocratie et droits de l'homme. Contribuição aO COLÓQUIO DO CONSELHO DA EUROPA SOBRE DEMOCRACIA E DIREITOS HUMANOS, Tessalônica, Grécia, 24-26 de setembro de 1987.

18 Bonavides, Paulo. Un nouveau concept de démocratie directe et son applicabilité au Brésil. Discurso na XV CONFERÊNCIA NACIONAL DA ORDEM DOS ADVOGADOS BRASILEIROS, sobre o tema Ética, Democracia e Direito. Foz do Iguaçu, 4-8 de setembro de 1994. 
19 MBAYA, E.-R. Démocratie en tant que valeur universelle et exigence du progrès. Le cas de l'Afrique. Discurso de abertura na XV CONFERÊNCIA NACIONAL DA ORDEM DOS ADVOGADOS BRASILEIROS, sobre o tema Ética, Democracia e Direito, Foz do Iguaçu, 4-8 de setembro de 1994.

20 Certo tipo de organismo político da África Negra, compreendendo um território sobre o qual se exerce a autoridade de um chefe de tribo (N.T.).

21 Mbaya, E.-R. Cent dix ans depuis la Conférence de Berlin. Les guerres qui partagent l'Afrique. Comunicação ao CONGRESSO DA ASSOCIAÇÃO LATINO-AMERICANA DE ESTUdOS SOBRE A ÁFRICA E A ÁSIA, Vina del Mar, Chile, 1995.

22 Id. Rapport dialectique entre Etat de droit, démocratie et droits de l'homme pour la promotion de la paix sociale en Afrique. Paris, Obra coletiva, Présence Africaine, 1995.

Etienne-Richard Mbaya é professor da Faculdade de Direito da Universidade de Colônia. Participa do Instituto de Teoria Geral de Direito, do Estado e de Filosofia Política e do Instituto de Direito Público Internacional e de Direito Público de Estrangeiros.

Palestra feita pelo autor em 30 de novembro de 1995 no Instituto de Estudos Avançados da Universidade de São Paulo, Brasil.

Tradução de Gilberto Pinheiro Passos. O original em francês - Genèse, évolution et universalité des droits de l'homme face à la diversité des cultures - encontra-se à diposição do leitor no IEA-USP para eventual consulta. 